\title{
Using Ecotech Architecture as an Effective Tool for Sustainability in Construction Industry
}

\author{
Azam Sadat Mozhdegani \\ Department of Architecture \\ Islamic Azad University \\ Kerman Branch \\ Kerman, Iran
}

\author{
Reza Afhami \\ Department of Architecture \\ Islamic Azad University \\ Kerman Branch \\ Kerman, Iran
}

\begin{abstract}
Ecotech architecture can be used as an effective strategy to minimize energy consumption and enhance the satisfaction of construction industry beneficiaries in the Middle East. The use of ecotech principles has been employed in different parts of the world. However, following a universal approach is not possible as local conditions are always to be considered Applications and examples of ecotech architecture are investigated in this paper. A proposed building design for the Cheetgar region in Tehran is also briefly demonstrated. A further insight on Masdar city in Abhu Dabi is provided. An overall discussion is made and key conclusions are drawn.
\end{abstract}

Keywords-architecture; ecotech; Persian Gulf; Cheetgar; architectural form; Masdar City; energy consumption; environment.

\section{INTRODUCTION}

Sustainable strategies are gradually implemented in the construction industry. Such a strategy requires the phasing out of conventional technologies and replacing them with sustainable ones, more compatible with the environment [1]. Efficient use of water resources is one of the most important approaches to achieve clean architecture and move towards to the principles of ecotech. From one perspective, environmental based design defines the foundation of ecotechonogical architecture. Planning to construct buildings with special characteristics in a specific area requires a comprehensive and systemic approach [2]. Although these definitions define the scope of environmental management in architecture effectively, it is closely related to equipment and facilities. It is very important to develop suitable strategies for environmental management by adjusting the temperature, good ventilation, sound level, etc. All these define the real conditions of comfort for the people and residents through construction and engineering [3]. Energy consumption and greenhouse gases emission of buildings have been investigated in [4]. Increasing energy efficiency is essential to change the pattern of world energy consumption [5] and thus reduce greenhouse gas emissions.

According to COM 815 program that is a subject of emphasis by European Union, all EU members are seeking to reduce of energy consumption by $20 \%$ and limit and reduce annual cost per household to less than 1000 euros. Therefore, the saving can create more than two million jobs by 2020 in EU countries. Despite the recognition of this approach by all EU members, the results of the field surveys are disappointing and few effective efforts are done to achieve potential reduction identified in the outlined vision [6]. Energy performances of buildings are defined according to different rules and mechanisms. One way in this regard is Near Zero Energy Buildings (nZEB). This goal seems very ambitious and it needs the cooperation of several sectors and different fields. Using this strategy seems evidently in ecotech architecture. Considering all the aspects and difficulties of this law, the members are less likely to implement its provisions. Applying ecotech architecture is suggested firstly for public buildings because of its high cost and the need for specific and innovative technologies as well as the obligation to have a systematic and comprehensive perspective. Different countries should reach near-zero energy buildings standards in public applications through special ecotech architectural principle and utilizing environmentally efficient thermal insulation by the year 2018 .

\section{ECOTECH ARCHITECTURE EXAMPLES}

Modern architecture focuses on the construction of structures with natural ventilation and light, employing various technologies and techniques including computer simulation [7]. Apparently, failure to meet users' demands in modern buildings is the cause of changes [8]. A yeast production building in Malta (location very similar to Tehran) sets a good example covering all American and European requirements in the field of air conditioning and energy in an industrial building. This building is very different from other similar plants. The application of massive ventilation towers has made it a good sample of modern industrial buildings. Placing the ventilation openings in the roof of the building provides the possibility of conditioning half of the air from the internal area within an hour. With regard to exothermic process of yeast production and chemical conversion fitting the proliferation, it is essential to keep ambient temperature always between 5 and $7^{\circ} \mathrm{C}$. Uncoated additional facades are used to enhance temperature regulation, allowing the building to "breathe" normally [8]. In any ecotech architecture approach the aim is to balance diverse 
factors such as urban development, design, attention to function, appearance and the response to users' needs [9]. The first executive steps about new attitude to ecology and architecture can be seen in the complex form buildings of Willis -Faber Dumas-Norman Foster in Ipswich. Creating a small glazed area to the building and designing deep plans maintain most of the energy inside the building. The introduction of a central atrium enhances the use of sunlight. The presence of glass walls suspended in facades also helps absorbing sunlight in offices. A garden with short plants and grass has been created on the roof and the employees can enjoy it in rest hours [9]. The Stansted Terminal at London airport has similar advances in the use of sunlight. The outer shell of the building depicts a new approach to the design transportation buildings in Europe. Properly designed forms for columns have created the focus in the ceiling with tree-like structures [10] (Figure 1).

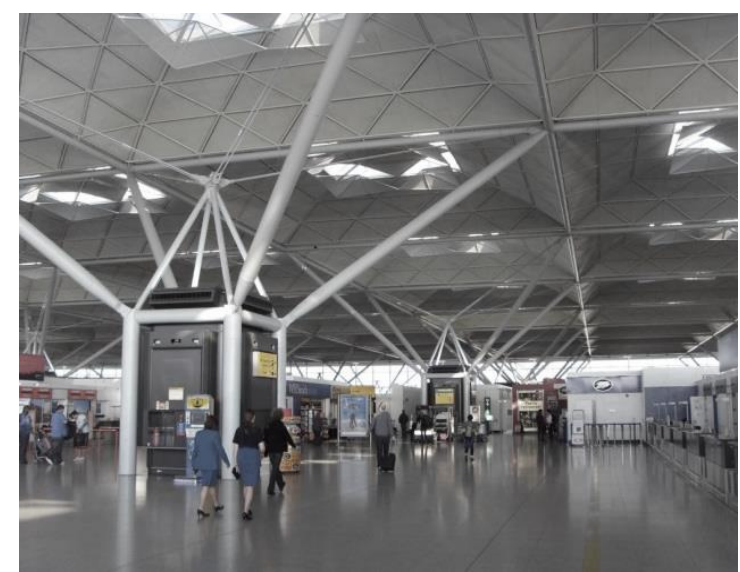

Fig. 1. A view of the interior space of the Stansted Terminal.

Another building that represents the process of ecotech architecture is found in Duisburg, Germany. The city was dependent on the steel and coal industry that ran into serious decline. To regenerate itself it looked at the introduction of the microelectronic industry as a new form of industry for the city, and thus producing an overall master plan for an inner city center, which led to a group of three buildings. The first of those is the Telematic Center, a flagship building to show how the city could rework itself. In some ways, the external appearance of this has some similarities with the Willis-Faber in Ipswich, a sheer glass wall. The overall energy strategy is based on solar collectors on the roof and the city's main gas supply provides the rest of the energy. The gas is turned into energy through a cogenerator producing the electricity for all the power and lighting requirements and also heat which, when linked with the solar collectors on the roof, transformed it into the cooling system through the absorption cooling machine, that cooling taking the form of a chilled water system in the ceiling [10] (Figures 2 and 3).

The most important and most successful example of ecotech architecture is the changes and improvements on the dome of Reichstag. Many changes have been done in this old building to respond new demands and new applications. Moreover, this place is regarded as the symbol of Berlin, hence, it has become a special and different place. Using a dome as the main part of the air conditioning and skylight for the first time. Besides, a movable cover on the dome follows the path of the sun. Solar cells on the side of the dome design provide the required electrical energy supply [11]. Airflow applies a negative force on the dome and pulls hot air out. In addition to sunlight, the consumed energy is supplied by natural fuels such as sunflower. The Reichstag building produces $94 \%$ less carbon dioxide than buildings of similar volume. The energy reservoir is a water reservoir and it is located at a depth of 300 meters which is used to regulate the building's temperature [11].

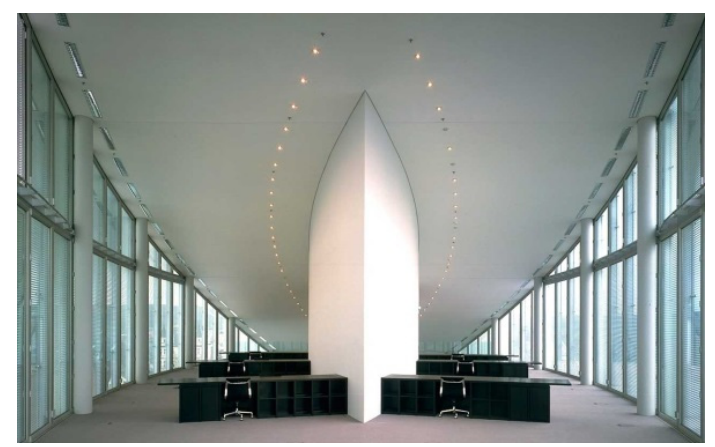

Fig. 2. Interior and shallow of the plan space inside the shell, a three-layer the building.

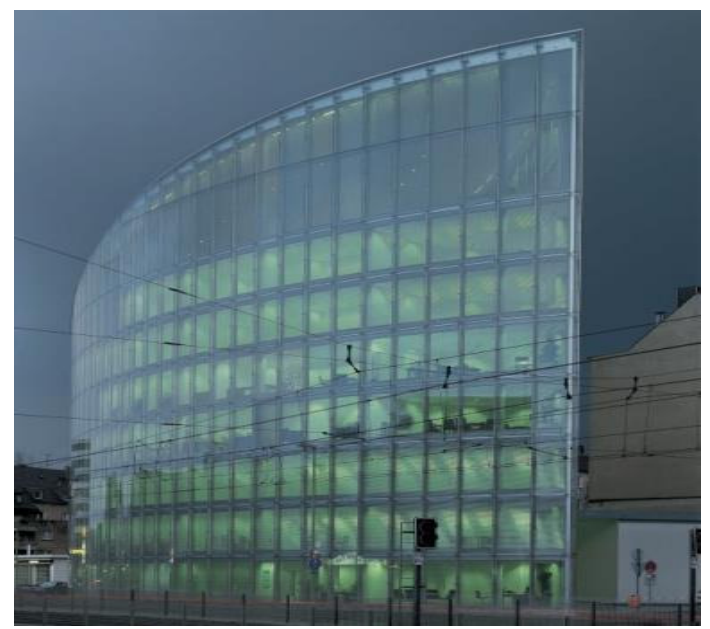

Fig. 3. Exterior view of the building and its transparency.

\section{A PROMISING DESIGN FOR TEHRAN, IRAN}

It is observed from the latest developments in Tehran that there is a gap between the ecotech principles and the actual situation. Increasing population growth, geographical expansion, ethnic diversity, uneven development and the lack of attention to environmental issues and renewable energies will reflect a great transformation in physical transformation of Tehran. However, ecotech design is a major priority for Tehran with Cheetgar region providing the capability to be introduced as a pattern for other regions due to its local characteristics and optimal access. A proposed ecotech building structure has three 
upper floors and an underground one that has various functions according to requirements and needs. Instances from the design are shown in Figures 4-8.

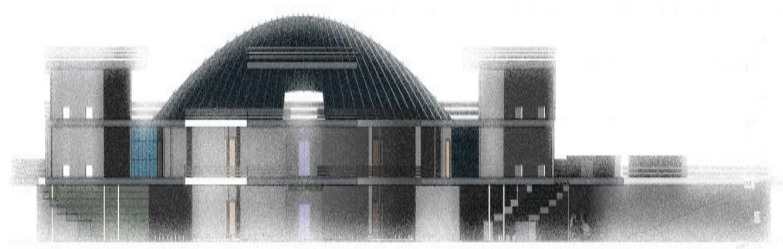

Fig. 4. Cross-section of the proposed building

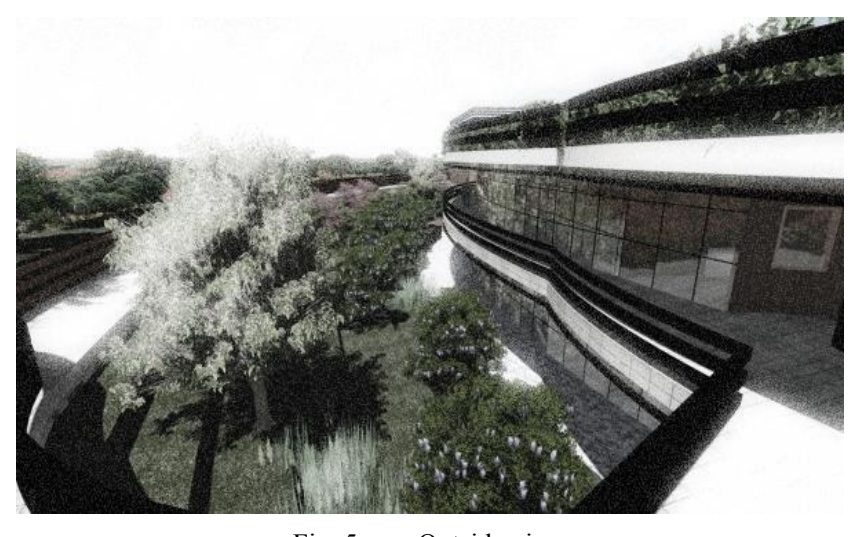

Fig. 5. Outside view

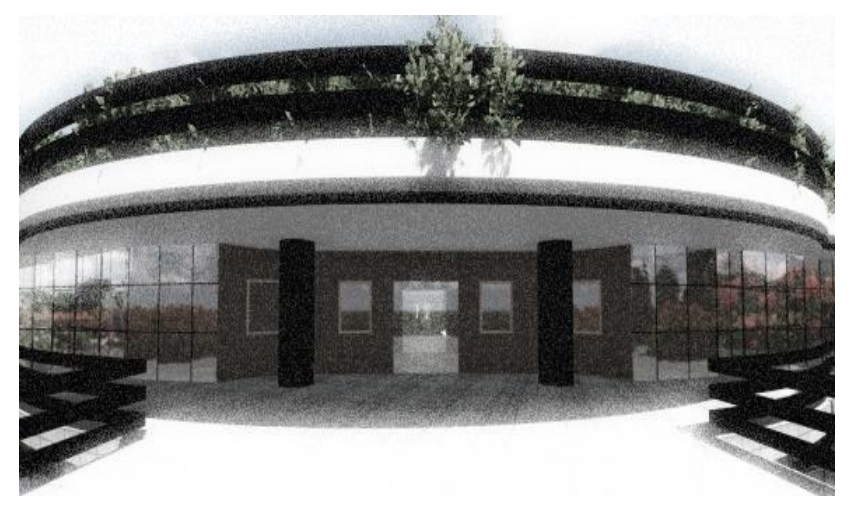

Fig. 6. Main entrance

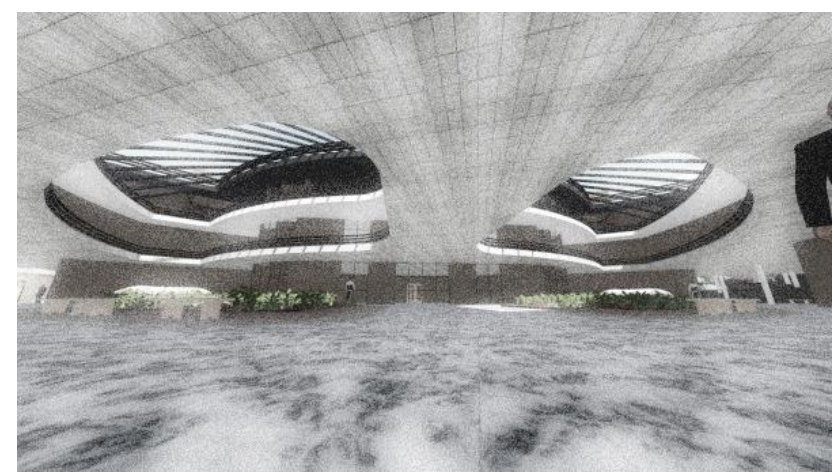

Fig. 7. Basement view

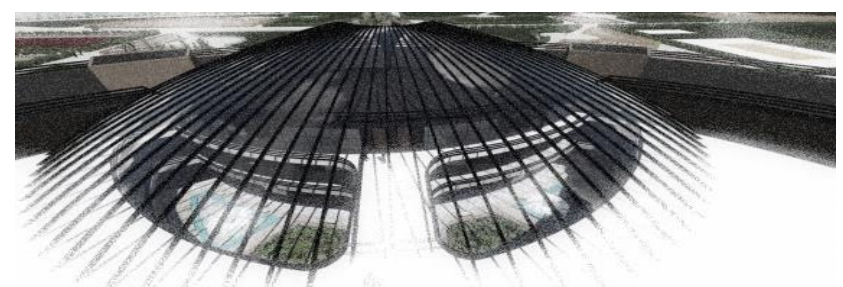

Fig. 8. From the entrance to the first floor terrace

\section{THE CASE OF MASDAR CITY, ABU DHABI}

In the ecotech and energy field, the following major issues should be considered:

- Innovation and Experience. Innovation requires creative talents and money usually (not always) is regarded as an essential and motivating factor for it. Therefore, it has been accepted traditionally that authorities must invest for accomplishment of creative people's capabilities.

- Engaging in Clear and Worthwhile Goals. Energy supply and benefit from it will form a complex system whose complexity will be increased by the inclusion of conditions and methods of financing. Comprehensive attention and understanding of the system is essential. Otherwise serious problems will be imposed on the system [14]. The infrastructures and supply needs are of particular importance.

- Balance. Establishing economic, social, and environmental balance are recognized as dimensions of ecotech architecture and as critical factors.

Masdar City is in Abu Dhabi, UAE and it is indeed a carbon neutral city with minimum waste emission. It indicates the application of ecotech architecture in Middle East, on an independent desert city. The city will be the home of 50.000 residents and 1.500 businesses upon completion. It will present 70 thousand jobs [12]. Masdar City has a great advantage in terms of attracting talented people (e.g. students and traders) as resources are generously provided by the government. Such an approach would identify the city as an international laboratory for suitable investors. In this way, it facilitates attracting talents and new investments [13]. Public spaces include landscaping and water flow as evaporative cooling. A multi-functional complex includes various sections such as laboratories, accommodations, variety of social spaces like gyms, restaurant, cafes, research centers, and meeting halls. Apartments are designed in one-room, two-room, and three-room complexes constructed with high density blocks [11]. Despite the expected objectives and benefits, the city design is facing serious challenges as a work in project [15]. A deeper insight on Masdar City and the application of multi-functional buildings as a complex provides valuable conclusions that may be classified in the following general groups:

- The use of accurate and update equipment is very important for measuring greenhouse gas emissions and reducing fossil 
fuel consumption in order to monitor the process of constructing sustainable cities.

- The creation of sustainable forms of transportation, agriculture, environment, and energy can bring economic interests. With investments of around five billion dollars in sustainable cities, a three-time return on investment can be experienced in six years. Masdar City is trying to reduce operating costs with the help of selling materials resulting from filtration and carbon dioxide recovery.

- The sharp decline in oil prices brings forth financing problems for any large-scale construction project in Middle East. These should be solved through proper management of portfolio and using rational strategic plans.

- Using multi-functional urban experiences in hot and dry area with obstacles and problems such as water shortages and overproduction of carbon dioxide can be important and administrative strategies to reduce the pollution in cities around the world.

\section{DISCUSSION}

The ecotech approach aims to pay particular attention to energy, environment, and social and economic aspects of modern architecture. The main problem in this regard is the lack of standards and principles for how to do things. A short investigation of major ecotech projects reveals the following key points:

- Enforcing an ecotech architecture approach on a city can cause a construction boom and also improve the life of residents, attract investments and tourism.

- There are no standard ecotech design guidelines that can be implemented on all cases. Each region needs a different strategy according to its own climatic, historical, and economic situation.

- Tehran has a high potential for such applications, having a large population and high density as well as warm and dry climate and varied architectural styles. Considering average income and per capita costs, the construction of ecotech buildings seem suitable for investors.

\section{CONCLUSION}

Ecotech architecture is a topic of major interest for the construction industry in Middle East due to the local environmental factors such as the climate, in combination with certain factors that demand the consideration of strategies to minimize energy consumption. In this paper, a short investigation in such applications is provided. A discussion is conducted and some key conclusions are drawn.

\section{REFERENCES}

[1] M. Asif, "Growth and sustainability trends in the buildings sector in the GCC region with particular reference to the KSA and UAE", Renewable and Sustainable Energy Reviews, Vol. 55, No. 3, pp. 1267-1273, 2016

[2] W. Pan, "System boundaries of zero carbon buildings", Renewable and Sustainable Energy Reviews, Vol. 37, No. 2, pp. 424-434, 2014
[3] S. Marczak, D. Damian, "How interaction between roles shapes the communication structure in requirements-driven collaboration", 19th IEEE International Requirements Engineering Conference, pp. 47-56, 2011

[4] S. Lechtenbohmer, A. Schuring, "The potential for large-scale savings from insulating residential buildings in the EU", Energy Efficiency, Vol. 4, No. 2, pp. 257-270, 2011

[5] E. E. Roadmap, 2050-COM (2011) 885/2. Brussels: European Commission, 2011

[6] European Commission, Communication on Energy 2020: A Strategy for competitive, sustainable and secure energy, COM (2010) 639/3, European Commission, Brussels, 2010

[7] M. I. Sayyadzadeh, I. Shiravi, Ibrahim, H. Sadeqi, A. Sadeqi, "Effect of using heat recovery ventilation system in the building", 1st biennial conference on Persian Gulf oil, gas and petro chemistry, 2016

[8] M. Iommi, "The natural light in the Italian rationalist architecture of Ex GIL of Mario Ridolfi in Macerata. The virtual reconstruction and the daylight analysis of the original building”, Energy and Buildings, Vol. 113, No. 1, pp. 30-38, 2016

[9] H. Niroumand, J. A. Barcelo, C. J. Kibert, M. Saaly, "Evaluation of Earth Building Tools in Construction (EBTC) in earth architecture and earth buildings", Renewable and Sustainable Energy Reviews, 2016

[10] A. Scott, Dimensions of sustainability, E \& Fn Spon, 1998

[11] M. Golabchi, Technology and Architecture: A Study of Faster Norman Works, Tehran University Press, Iran, 2012

[12] S. E. Lee, P. Braithwaite, J. M. Leach, C. D. Rogers, "A comparison of energy systems in Birmingham, UK, with Masdar City, an embryonic city in Abu Dhabi Emirate", Renewable and Sustainable Energy Reviews, Vol. 65, No. 2, pp. 1299-1309, 2016

[13] F. Cugurullo, "How to build a sandcastle: An analysis of the genesis and development of Masdar City", Journal of Urban Technology, Vol. 20, No. 1, pp. 23-37, 2013

[14] D. R. Lombardi, M. Caserio, R. Donovan, J. Hale, D. V. Hunt, C. Weingaertner, L. Jankovic, "Elucidating sustainability sequencing, tensions, and trade-offs in development decision making", Environment and Planning B: Planning and Design, Vol. 38, No. 6, pp. 1105-1121, 2011

[15] D. Reiche, "Renewable energy policies in the Gulf countries: A case study of the carbon-neutral Masdar City in Abu Dhabi", Energy Policy, Vol. 38, No. 1, pp. 378-382, 2010 